\title{
'I Think It Will Be Like This Forever': How Family Narratives Affect Participation in a Childhood Weight Management Intervention
}

\author{
Dan Grabowski ${ }^{1, *} \mathbb{\infty}$, Anne Martine Aaberg Mortil ${ }^{1}$, Didde Hoeeg ${ }^{1}\left(\mathbb{D}\right.$, Maj-Britt Lundsgaard Hansen ${ }^{2}(\mathbb{D}$, \\ Birgitte Højgaard Roikjer ${ }^{2}$ and Grete Katrine Teilmann ${ }^{2}$ \\ 1 Health Promotion Research, Steno Diabetes Center Copenhagen, Niels Steensens Vej 2, \\ 2820 Gentofte, Denmark; anne.martine.aaberg.mortil@regionh.dk (A.M.A.M.); \\ didde.hoeeg@regionh.dk (D.H.) \\ 2 North Zealand Hospital, Dyrehavevej 29, 3400 Hillerød, Denmark; \\ maj-britt.lundsgaard.hansen@regionh.dk (M.-B.L.H.); birgitte.hoejgaard.roikjer@regionh.dk (B.H.R.); \\ grete.katrine.teilmann@regionh.dk (G.K.T.) \\ * Correspondence: dan.grabowski@regionh.dk
}

Citation: Grabowski, Dan, Anne Martine Aaberg Mortil, Didde Hoeeg, Maj-Britt Lundsgaard Hansen, Birgitte Højgaard Roikjer, and Grete Katrine Teilmann. 2021. ‘I Think It Will Be Like This Forever': How Family Narratives Affect Participation in a Childhood Weight Management Intervention. Social Sciences 10: 175. https://doi.org/ 10.3390/socsci10050175

Academic Editor: Nigel Parton

Received: 4 March 2021

Accepted: 14 May 2021

Published: 17 May 2021

Publisher's Note: MDPI stays neutral with regard to jurisdictional claims in published maps and institutional affiliations.

Copyright: (c) 2021 by the authors. Licensee MDPI, Basel, Switzerland. This article is an open access article distributed under the terms and conditions of the Creative Commons Attribution (CC BY) license (https:/ / creativecommons.org/licenses/by/ $4.0 /)$.

\begin{abstract}
The family represents the cause of as well as the solution to childhood overweight in many family-based childhood weight management interventions. Involving the family also entails involving the individual family members' experiences with, attitudes towards, and understandings of obesity. This study explores how families with life-long experiences of overweight manage and experience a family-based childhood weight management intervention in Northern Zealand in Denmark. The analysis is focused on family narratives and their temporal character. The families' narratives about overweight and past weight management interventions are crucial to how they understand and manage the present intervention. Additionally, the families expect the focus on weight management to continue to be a constant part of their everyday life. The paper concludes that the understanding of weight management in interventions should take its point of departure in the life-world, which the individual family creates through members' narratives about overweight.
\end{abstract}

Keywords: childhood; obesity; narratives; intervention; family

\section{Introduction}

The WHO frames childhood obesity as one of the most serious public health challenges of the 21st century (WHO 2018). Childhood obesity is associated with chronic diseases such as diabetes type 2, asthma, and cardiovascular diseases-sometimes with preliminary stages already in childhood (Lobstein and Jackson-Leach 2016; Rasmussen et al. 2015). A child with obesity faces a four-fold greater risk of being diagnosed with type 2 diabetes by age 25 than a healthy weight child does (Abbasi et al. 2017).

When treating childhood obesity, interventions are often directed at the whole family. In recent Cochrane reviews on interventions to reduce childhood overweight and obesity, the majority of trials included parents or family members (Mead et al. 2017; Oude Luttikhuis et al. 2009). However, these recent reviews all conclude that family-based interventions lead to only small decreases in children's weight (Al-Khudairy et al. 2017; Mead et al. 2017; Oude Luttikhuis et al. 2009). The concept of adherence is most often used in relation to medical treatment but is also relevant to implementation of lifestyle changes (Lee et al. 2008). It is well-known that poor adherence to behavior change in lifestyle interventions is widespread, particularly in the long-term (Middleton et al. 2013).

Few studies have described exactly how families are involved in the given intervention, and there seems to be great variation in the intensity of family focus and involvement across studies (Lowry et al. 2007). The concrete effort of involving the family is often neglected and genuine involvement therefore rarely takes place (Hoeeg et al. 2020a, 2020b). 
However, it is well-established that parent involvement is vital to both achieving and maintaining weight loss (Eg et al. 2017). This suggests that analyzing family experiences within a family-based intervention, as well as discussing how these experiences are related to how the intervention is implemented into the everyday lives of these families, should be incorporated into the research. A review highlights the need for more rigorous studies to enhance our knowledge regarding factors related to adherence. Identification of such factors could have important implications for program improvement, ultimately improving the effectiveness and cost-efficiency of lifestyle modification programs (Leung et al. 2017).

In the social sciences, childhood obesity comes across as a complex phenomenon with multiple non-medical influencing factors such as structural barriers to healthy eating, the food industry, socioeconomic factors, lifestyle choices, and environments (Andreassen et al. 2013, p. 1333; Brownell and Horgen 2004; Nestle and Jacobson 2000). A number of critical scholars have questioned the existence of a 'Childhood Obesity Epidemic'. Boero (2007) argues that media hype has been a driving factor in constructing the 'Childhood Obesity Epidemic' as a problem. According to Boero, childhood obesity lacks a clear pathological basis (Boero 2007). In a similar line, de Vries (2007) problematizes the medicalization of obesity that goes along with the term epidemic (de Vries 2007). According to Conrad (2007), the number of life problems that are defined in medical terms has increased enormously over the last few decades (Conrad 2007, p. 3). Conrad argues that individualization, which is a part of medicalization, removes the focus from the social environment and calls for individual medical interventions rather than more collective or social solutions (Conrad 2007 , p. 8). Thereby, medicalization turns obese children into patients who must be cured. Thus, the construction of childhood obesity as a medical problem has made it into an object of intervention.

According to Boero, children themselves are never blamed for obesity but their caregivers are (Boero 2007, p. 55). Currently, we see a trend in which interventions to treat childhood obesity are family based (Mead et al. 2017; Oude Luttikhuis et al. 2009). According to Golan (2006), family members are important actors in the weight management process (Golan 2006). Hence, family members represent both the ones to blame for and the solution to childhood overweight. However, the term 'family based' is often not well-defined (Skelton et al. 2012). Even though involvement of the family has been widely recognized as an essential element of interventions to treat childhood obesity, the family-based interventions' effects on weight loss remain limited (Al-Khudairy et al. 2017; Mead et al. 2017; Most et al. 2015; Oude Luttikhuis et al. 2009).

In the medical literature, weight loss and weight stabilization are often the determinants of whether an obesity intervention is seen as successful or not. However, family-based childhood obesity interventions might have a range of unintended effects that are damaging to the persons involved. The changes required in a family-based intervention may create friction and conflicts between parents and children, expose fragile relationships, and threaten family dynamics (Arai et al. 2015; Eg et al. 2017). Andreassen et al. (2013) argue that parents of young obese children experience moral dilemmas and try to hide the fact that the children are supposed to lose weight in order to protect them from feeling stigmatized (Andreassen et al. 2013). In a study of a family-based childhood weight management intervention, Hoeeg et al. argue that the children often end up feeling stigmatized within the family because the children have to adhere to specific rules (Hoeeg et al. 2018).

To date, few studies have explored how families manage a given weight management intervention (Lowry et al. 2007). Skelton et al. argue that, if family-based approaches are to be truly rooted in the family, there is a need for an improved understanding of how families manage the intervention on a day-to-day basis (Skelton et al. 2012). This suggests that there is a need to explore families' experiences and how these experiences affect familial involvement in interventions and incorporate it into research. Furthermore, such insights would nuance the implications of childhood obesity interventions in families' lives. It is important to acknowledge that obesity interventions are not only a question of weight. 
Involving families also means involving individual family members' experiences with, attitudes towards, and understandings of overweight.

In a study of life-long and transgenerational experiences with overweight, Grøn (2017) argues that processes of weight gain and weight loss remain mysterious for the families she has followed. However, this alienation emerges in the context of the ordinary and the most intimate spheres: the home and the family (Grøn 2017). Grøn argues that obesity 'runs in the family' and is not an individual affair (Grøn 2017). Thereby, Grøn is concerned with the social spread of obesity and its inherent relationality. According to Grøn, there was no shortage of credible explanations for obesity in the family histories revealed in her fieldwork, but they did not add up (Grøn 2017). Yet, all the stories told concerned family. Thus, according to Grøn, intimate networks of relatedness are the most relevant units of analysis when focusing on familial experience with weight management interventions (Grøn 2017).

We take a similar starting point as Grøn by focusing on families' narratives of their perceptions of their involvement in weight management efforts as well as on the notion that the individual is part of webs of narrative mutuality. The present paper takes a novel anthropological approach to explore how a family-based childhood weight management intervention is managed and experienced by families who have previous experience of overweight and interventions. It is important to stress that this is not an evaluation of the intervention and its outcomes. The sole objective is to explore how family narratives and their temporal character influence the ways these families experience and manage the intervention in the context of their lifelong experience with health and weight management. The objectives are: How does this life-long experience with overweight and weight management affect the family's participation in a family-based childhood weight management intervention? How do narratives about overweight influence intra-familial management of an intervention?

\section{Methods}

\subsection{Setting}

The weight management intervention under study here is defined as a shared-care project, shared between the pediatric unit at Nordsjælland's Hospital in Denmark and eight municipalities in Northern Zealand. The intervention is aimed at children with a BMI over the 99th percentile and their families. The intervention consists of an initial examination of the child at the pediatric unit at Nordsjælland's Hospital and meetings with a health nurse on a regular basis (4-6 times a year) in the family's local municipality. At the initial visit to the pediatric clinic, the pediatricians screen for underlying biomedical causes for obesity and possible complications and take anthropometric measures. The pediatricians perform a lifestyle interview with a questionnaire, which covers eating behavior, dietary habits, family history of obesity, exercise, transportation patterns, possible experiences of bullying, and family background. Additionally, the pediatricians calculate the parents' BMI. The pediatrician gives the family a treatment plan, which all family members are to follow. The aim of the treatment plan is to promote lifestyle and behavioral changes and to support the child and family in informing and adjusting the surroundings. The follow-up visits are conducted in the child's local municipality by trained nurses who have access to the child's treatment plan as well as the data from the baseline visit at the hospital. The nurse and the family discuss treatment progression and the nurse takes anthropometric measures at all follow-up visits. After a year, the procedure from the initial visit is repeated in a second family visit at the hospital. The families can remain a part of the intervention until the child is 18 years old or longer if necessary.

\subsection{Recruitment, Interviews, and Analysis}

The healthcare professionals responsible for the intervention did the initial recruitment of families. They obtained approval from the families enrolled in the intervention that a researcher could contact them and invite them to a family interview. In total, they asked 
52 families and 38 of these families agreed to be contacted. The reasons for not wanting to participate were considered confidential and therefore not forwarded to the research team.

We contacted the 38 families in random order and after doing 21 interviews, the research team agreed that data saturation had been achieved. The remaining 17 families were informed that their participation was not needed after all.

We conducted semi-structured interviews with 21 families participating in the weight management intervention. The interview guide included topics such as everyday life in the family, familial history of overweight and obesity, implementation of the treatment plan, the initial examination at the hospital, the meetings with the health nurses, and their overall experience of the intervention. In all, 61 individuals participated in the 21 family interviews (see Table 1$)$. The interviewees were 22 children (14 boys and 8 girls) who were enrolled in the intervention and 18 mothers, 9 fathers, and 12 other family members (siblings, grandparents, and partners). The children enrolled at the pediatric unit were between 11 and 17 years at the time of the interview. Between 2 and 6 family members participated in each interview, representing different family forms. All the interviewed families had been in contact with either the health nurse or the hospital within a six-month period prior to the interview. Families from all eight collaborating municipalities are represented in the study (thereby representing both urban and rural areas), and they differed significantly in socioeconomic background.

Table 1. Characteristics of interviewed families.

\begin{tabular}{|c|c|c|c|}
\hline & & Number & In Total \\
\hline \multicolumn{3}{|c|}{ Children/adolescents (enrolled in the intervention) } & 21 \\
\hline & Male & 8 & \\
\hline & Female & 13 & \\
\hline \multicolumn{4}{|c|}{ Children's age (years) } \\
\hline & 11 & 2 & \\
\hline & 12 & 5 & \\
\hline & 13 & 5 & \\
\hline & 14 & 1 & \\
\hline & 15 & 3 & \\
\hline & 16 & 1 & \\
\hline & 17 & 4 & \\
\hline \multicolumn{3}{|c|}{ Family members (in interview) } & 38 \\
\hline & Mother & 17 & \\
\hline & Fathers & 9 & \\
\hline & Others * & 12 & \\
\hline \multicolumn{3}{|l|}{ In total } & 59 \\
\hline
\end{tabular}

All 21 interviews were conducted in the family home. This was done to create a safe environment and to give the researchers insight into the familial setting. This insight made it easier to keep the interviews focused on and relevant to the families.

Interviewing the family members together has several advantages. In order to explore joint narratives, it is important to interview the family members together. Interviewing and thereby studying the family members together is especially valuable when examining how the narratives are constructed in real life through the interdependent relations within the family, as it provides access to this ongoing construction of the narratives in real time. A family is always more than the sum of its individual members, and family interviews allow researchers to gain insight into the hidden dynamics of family life (Asstedt-Kurki et al. 2001). Dialogues between family members can unfold in a family interview, enabling insight to be gained into processes and discrepancies between family members (Reczek 2014). Family members live together and share (to varying degrees) ev- 
eryday life, but they may have different views on the family's everyday self-understandings and overall identity.

A potential disadvantage of interviewing family members together is that significant controversies may be left unsaid because there is a risk of reproducing inequality among family members and there often is a tendency to achieve a consensus and thereby neglect to express disagreements (Reczek 2014). Thus, there is a risk that the children in the study were influenced directly or silenced by their parents or older siblings.

The families participated in interviews after giving their informed written consent. The interviews were recorded and transcribed verbatim. We have anonymized all interlocutors and omitted any information that could potentially reveal their identity. The health professionals responsible for the intervention did not have access to the transcribed interviews. According to Danish legislation, interview studies require no approval from an ethics committee. The study followed the codes of ethics found in the Helsinki II Declaration. Moreover, the study was approved by the Danish Data Protection Agency (Rec. No.: $\mathrm{NOH}-2016-024)$.

Interview transcripts were coded and analyzed thematically using Nvivo 10.0. The interviews were transcribed verbatim, iteratively analyzed in Danish, and then categorized using radical hermeneutics, which are a set of guidelines for content analysis that, as a combination of hermeneutics and constructivism, manage to simultaneously be empirically founded and theoretically complex (Rasmussen 2004). Radical hermeneutics focuses on keeping a perpetual balance between theory, method, and data by acknowledging how all of these elements influence each other in an interconnected process. The use of radical hermeneutics also entails constant alternation between analyzing and interpreting, which means it is necessary to present interpretive aspects while presenting the results.

Radical hermeneutics is a validated methodology consisting of three steps of data analysis. The first step involves reading the data with a view to observing specifically selected differences in them. This observation in itself constitutes an interpretation rather than a description, and its task is to reduce the complexity of the data. Elements within the scope of the differences selected by the interpreter are extracted from the data. The second step involves making these elements the subject of interpretation as an observation of the differences employed. The third step involves interpreting the sum of these differences (Rasmussen 2004).

In the present analysis, this approach meant that the analytical process was developed in several steps as we delved deeper into the data. The first step focused on extracting issues of direct relevance to narrativity and temporality from the empirical data. The second step involved analyzing and interpreting the extracted data using the theoretical elements described below as an overall analytical strategy, and this step revealed the three main themes presented in the results section. The final step is then a separate interpretation of the data within each category-materializing as the findings presented for each of the themes.

Afterwards, the authors discussed the interpretations of the findings as part of a preliminary analysis, which focused the ensuing analytical steps on the concepts of narrativity and temporality, as these resonated with the empirical material.

\section{Theory: Narrativity and Temporality}

To thoroughly explore how the family-based childhood weight management intervention is managed and experienced by families who have previous experiences with overweight, we have included the theoretical concepts of narrativity and temporality in the analysis and interpretation of the empirical material.

Influenced by a broad 'narrative turn' in the social sciences, medicine, and psychiatry, medical anthropologists began exploring how stories make sense of and shape experience during the 1980s (Good et al. 2010, pp. 79-80). However, the use of personal narratives as research data has often followed a subjectivist approach, treating them primarily as an expression of the subject's psychological dispositions (Steffen 1997, p. 99). 
Steffen (1997) argues that experience can be shaped through the social interaction in the sharing of narratives (Steffen 1997, p. 110). According to Steffen, the dialectic and interpersonal quality of a narrative reflects the dialectical and interpersonal quality of experience, which Kleinman and Kleinman refer to when they define experience as an intersubjective medium of social transactions in local moral worlds (Steffen 1997, p. 106). The family context can be understood as a local moral world, where narratives are shaped through social interactions.

Ochs and Capps (1996) argue that temporality is a basic dimension of narrative (Ochs and Capps 1996, p. 23). According to Ricoeur (1980), the relationship between temporality and narrativity is reciprocal (Ricoeur 1980, p. 189). Ricoeur argues that a narrative unfolds in public time, which is not the anonymous time of ordinary representation but the time of interaction (Ricoeur 1980, p. 188). Thus, narrative time is time of being-with-others according to Ricoeur.

Ochs and Capps argue that the narrated past matters because of its relation to the present and the future (Ochs and Capps 1996, p. 25). According to Steffen, a narrative becomes a model of past experiences as well as a model for future experiences and to some extent contributes to the organization of social life (Steffen 1997, p. 110). Thus, a narrative is not just a way of giving meaning to the past, because it also directs experiences in the future. However, a narrative or plot does not represent fixed structures. Rather, a narrative is a constant negotiation of the relation between past, present, and future.

In the present paper, we aim to meet our presented objectives by exploring the families' participation in the family-based childhood weight management intervention through a theoretical lens of temporality, which lets us attend to the complexity of the experience of weight management. Furthermore, we focus on how families narrate overweight as a shared family problem and how these narratives influence the experience and the management of the intervention.

\section{Results}

'Nothing can surprise me anymore! I could work as a dietician by now. I've been chubby all my life, so I know exactly what to eat and what not to eat'. Camilla (mother to Anders, 11 years old)

Camilla knew a great deal about healthy food before she-and her 11-year-old son Anders-enrolled in the childhood weight management intervention under study in the present paper. Camilla has focused on weight management for years, but she has never experienced lasting weight loss. This extensive experience with overweight and overweight interventions is something she has in common with many other families enrolled in the intervention.

The analysis revealed three overall and interdependent themes: (1) The intervention as part of a continuous project; (2) Narratives about overweight as a shared family problem; and (3) The adoption of weight narratives. These themes will be presented separately below and then discussed cross-thematically in the ensuing discussion. Most of the findings are exemplified with quotes from one family or a few families to illustrate the findings in a thorough manner. This is not because the particular finding was only detected in a single family - it is a way of understanding broad phenomena through standout cases.

\subsection{The Intervention as Part of a Continuous Project}

Christoffer is 15 years old and is enrolled in the current intervention. Formerly, he and his mother had been enrolled in other weight management interventions at the pediatric clinic at Nordsjælland's Hospital for many years. Pia, Christoffer's mother, says:

'I guess it's been ever since Christoffer was eight years old that we've been doing this weight project. Some of it has been going on in other settings also, but we've been enrolled at the clinic in the hospital the whole time as well'. 
Pia and Christoffer do not separate the present intervention from their earlier enrolments at the pediatric clinic at Nordsjælland's Hospital as they refer to it as one continuous project that has been going on for half of Christoffer's life. This diverges from an understanding in which an intervention is a set period with a clear beginning and end. Pia elaborates:

'We've had a long treatment process at Nordsjælland's hospital where we've been enrolled at the pediatric clinic on and off since forever. Christoffer has also been to a weight-loss camp and that went really really well and he actually maintained that weight for a long time. But within the last couple of years it has slowly begun to go the wrong way again. So we had to talk to the nurse and now we're here again. I guess it's just more of the same for us-there's not any big differences'.

Pia describes their enrolment in the present intervention as a case of simply starting once again. Thus, Pia and Christoffer felt they knew the routine before they enrolled in the intervention. Yet in their narration of the weight management process, Christoffer's stay at the weight-loss camp, where he stayed without his family, clearly stands out. Christoffer lost weight at the camp and he describes his stay as amazing. Pia told us that they distinguish between a life before and after the camp:

‘We often talk about life before the camp and life after the camp. We really learned about eating the right things and how to buy the right things at the supermarket.

Now we basically know what's good and what's bad. We finally learned'.

The weight-loss camp marks a turning point in the narration of the weight management process in Christoffer's family even though they had been a part of weight management interventions prior to it. When we asked whether Christoffer and Pia follow the dietary plan that is a part of the present intervention, Christoffer answers:

'We only follow the plans we were taught when I was at the camp. I totally know what to eat and we still go by those rules'.

Christoffer shows us that they have a dietary plan from the weight-loss camp on the fridge door. Additionally, Pia talks about a cookbook from the camp that she uses a lot. In many ways, it is their experiences from the camp that give meaning to the current intervention at Nordsjælland's hospital. Thus, the current weight management intervention is not a standalone experience for Christoffer and Pia, but is overshadowed, in their narrative, by Christoffer's stay at the camp.

Even though they have comprehensive experience with weight management interventions, it still makes sense for Christoffer and Pia to be enrolled in the current intervention:

'There hasn't been anything new in it for us this time. We know everything but we really still need someone to help us stay firmly motivated in this'.

The visits to the health nurse keep Christoffer and Pia's motivation up, and they both agree that they need regular weight control. For Christoffer and Pia, this need does not seem go away when the current intervention ends.

When we ask Anders, 11 years old, and his mother Camilla about the future, Camilla has similar reflections:

'I think it will be like this forever. That we will have to always think about overweight. I don't think we will ever be able to let go of that'.

\subsection{Narratives about Overweight as a Shared Family Problem}

Julius is 15 years old and enrolled in the intervention. Julius' little sister Marie, who is 12 years old, and both of his parents talk about their own experiences with overweight. Julius' mother Lene explains:

'Marie has overweight tendencies, I was very overweight when I was a child and it's the same with her dad. We've been part of this for a long time and we think about overweight all the time 'cause it's a constantly ongoing struggle at home. 
We have the same struggle about food every single day, so sometimes we just need a break from all that'.

For Lene it is necessary to take some breaks from the constant struggle with overweight in their family's everyday life. Lene speaks on behalf of the family when talking about overweight, and she very much tells a story of overweight as a shared family problem. Julius' parents, Lene and Hans, were overweight as children, but both lost weight years ago. Thus, their struggle against overweight began long before the current intervention. Julius also lost weight while participating in the intervention. However, the weight losses do not seem to have changed the understanding in the family, according to which overweight is a persistent threat-or a daily struggle, as Lene says.

Troels is 15 years old and lives with his mother Bettina. Bettina explains the overweight in their family as genetic:

'My younger brother, who we spend a lot of time with, weighs $140 \mathrm{~kg}$, right? Troels is a bit chubby, but I was a size 46 once. His father has also been chubbychubby, so I think it is in our genes'.

Even though Bettina has lost weight, she narrates overweight as a family problem and believes that their genes set them apart from others, for example Troels' friends:

'We think that it is really unfair, because actually we eat really, really healthy. His friends are like this (she shows with her hands that they are super-skinny) and they can just eat and eat and eat. Troels just can't do that, you see?'

Bettina finds it unfair that they constantly have to think about healthy eating, when others do not. Bettina understands the overweight in their genes as being decisive in their narrative, even though they eat healthy in comparison with Troels' friends. She elaborates:

'None of his friends like vegetables. None of them like any healthy stuff at all. As a mother it's extremely hard for me to see all of them constantly eat all the things Troels can't eat. When his friends come over they just sit there and eat cakes and crisps and drink sodas and it doesn't show at all. If someone like Troels would eat that it would show immediately'.

According to Bettina, Troels cannot engage in social life in the same ways his friends can, because the cakes, crisps, and sodas have a very different effect on him. According to Bettina, Troels and his friends have unequal (and unfair) conditions for being social.

When we ask Julius' family whether their participation in the weight management intervention has made them a healthier family, Lene answers:

Lene: 'No, it hasn't changed anything for us at all. For us everything changed when I got diabetes during my pregnancy with Julius-and I lost $12 \mathrm{~kg}$ in the last three months of the pregnancy. It was then that I started eating six meals a day'.

Hans: 'Yes, we've been living a very healthy life since 1999, right?'

Lene: 'Yes ... So no, this intervention hasn't changed anything at all for us'.

Julius' family has been very satisfied with the intervention even though it has not made them a healthier family or changed anything for them. The intervention has helped them stay motivated. Lene has made an effort to get Marie, Julius' little sister, enrolled in the intervention too. Even though Marie says that she is very different from Julius, she expects that she too will lose weight like Julius did. Lene's main motivation for enrolment in the intervention is to minimize Julius' and Marie's risk of diabetes:

'It's probably because I have this diabetes thing in the back of my mind all the time. I really don't like the thought of that. I will do anything I can to make sure my kids don't get diabetes. I want them to understand that unhealthy behavior has consequences'.

During the interview, Lene continuously returned to the risk of diabetes. Consequently, Lene's narrative regarding diabetes and the ensuing fear of diabetes has become a significant part of the way in which Julius' family manages the weight management 
intervention. Thus, the family narratives and prior experience with overweight in Julius' family influence the weight management intervention to the extent that the purpose and dietary instructions defined by the hospital are ignored.

\subsection{The Adoption of Weight Narratives}

Malene, 12 years old, was enrolled in the intervention at Nordsjælland's Hospital because her older brother Benjamin had been enrolled there before. At Malene's initial visit at the pediatric unit, she was excited when the pediatrician asked her whether she wanted to sign up for a weight-loss camp-just like her brother. Malene relates her own situation to Benjamin's experience with overweight:

'I have my brother Benjamin and I also have another brother. All of us have been overweight, so it's more or less been the same thing. First it was Lars and he got over it. Then it was Benjamin and he got over it. Now it is me and I'm now on the way to getting over it'.

Going through the same process as both her brothers significantly influences Malene's understanding of the weight management intervention, and within the family narrative it is now completely expected that it is Malene's turn to be enrolled in the intervention because the same challenges return with every child. Furthermore, Malene expects that she will pull through just as her brothers have done. Thus, Malene's and her brothers' narratives about overweight are very similar.

Benjamin tries to use his experience with the weight management intervention to help Malene, which often leads to arguments between him and his sister:

Vivi (Malene's mother): 'I know you've had conflicts the two of you. Benjamin has so much experience with this and now he sees his sister doing some of the same uncool things he did himself. He really wants to help her and then he tells Malene stuff she takes the wrong way and then she really takes it personal and nothing good comes out of it'.

Benjamin: 'It's exactly the same as I did back then. I took it personally as well, 'cause it feels like they're picking on you'.

Malene: 'I watched Benjamin do the same things back then. When mom said 'Benjamin, now you really have to watch out', Benjamin got really mad and left the room. So I'm basically stepping right into his footsteps and I do almost exactly the same things'.

In Malene's view, the intervention is scripted for her. It seems that Malene understands herself as being predisposed to go through the same weight management process as her brothers did. She even reacts in the same way as Benjamin did. Thus, overweight has a repetitive characteristic in their family narratives. Benjamin's narration of his weight loss structures how Malene now goes through the weight management intervention. When Benjamin tries to help Malene by passing on his experience with the weight management intervention, Malene takes it badly, just like Benjamin did when their mother tried to pass her experience with weight loss on to him. Thus, Malene's case illustrates how the narrated past is related to the present and future, but also that Malene's narrative is deeply entangled with her family members' narratives about weight management.

\section{Discussion}

In the analysis, we presented three themes: (1) The intervention as part of a continuous project; (2) Narratives about overweight as a shared family problem; and (3) The adoption of weight narratives. Below, we will discuss how these themes are interrelated and use narrativity and temporality to analyze and nuance these themes.

One common experience in these families is that overweight was an issue long before they enrolled in the weight management intervention in question. They all have extensive and life-long experience with overweight. According to these families, they do not acquire new knowledge by participating in the intervention, because — as they see it - they already know everything they need to know about healthy lifestyles from previous weight man- 
agement efforts and their general experience with overweight and health. Anders' mother Camilla says she knows so much about healthy eating that she could be a dietician herself at this point. Thus, the families did not understand themselves as lacking knowledge prior to the intervention and therefore they did not look for anything particularly new. Instead, the families' narratives about the weight management efforts they have participated in in the past are crucial to how they understand and manage the present intervention.

It becomes clear from these narratives that the families challenge a connection between a healthy lifestyle and weight loss, which is implied in the intervention. Julius' mother Lene says that the intervention has not made them a healthier family, because they were already healthy and have been since 1999. It is interesting given that Julius actually lost a lot of weight during the intervention. Still, the weight losses in Julius' family have not changed their understanding of overweight as a persistent threat. In a similar line, Troels and his mother Bettina do not think that they can eat what they want like other people. According to Bettina, they have to eat more healthy than other people because of the overweight in their genes. According to their family narratives, they are healthy families with a chronic weight management issue.

From a narrative and temporal perspective, the narrated past matters because of its relation to the present and the future. The present intervention does not lead to any major changes for the families, because it seems to be just another effort in an ongoing weight management project that has lasted for years and years. Central in this project is the constant threat of overweight. Pia, Christoffer's mother, says that 'it ha[d] slowly begun to go the wrong way again' within the last couple of years before they enrolled in the present intervention. With 'the wrong way', Pia primarily refers to their motivation for weight management and not their weight. They need someone to help them stay focused on the threat of overweight. The families' focus on weight management transcends the period of the intervention, which the health professionals, in contrast, treat as bounded and limited to the proposed intervention period. In the families, there is no well-defined beginning and end of the process of losing weight. From a temporal perspective, the families see this threat of overweight as an integral part of both the past and the present, and none of the families seem to question the established fact that overweight and the continuous struggle with weight management will be a part of the future as well. Yet, it is important that the threat of overweight is independent of weight losses and healthy eating in the family narratives.

Even though the families did not say that they explicitly benefitted from the intervention in terms of significantly improved health behavior, they all seem to be rather satisfied with the intervention and their own level of participation in it. It is a striking finding that the families feel comfortable with their participation in the intervention whether they experienced a weight loss or not. The intervention helps the families stay motivated, which is crucial for them. Hence, it is relevant to ask what constitutes success for whom in a weight management intervention. Additionally, the weight management intervention fits their narratives and self-understanding as a family with weight management issues. In other words, they collectively expect to be like this forever, and weight management interventions merely confirm the expectation that they continuously need to focus on the threat of overweight.

Furthermore, the interconnectedness of weight narratives is a central theme in our analysis. Through a focus on narratives' intersubjective qualities, we argue that family members' narratives contribute to a shared understanding of weight management. The family context can be seen as a local moral world, in which both experience and narratives about overweight are shaped through social interactions between family members. When all family members have experiences with overweight and weight management and share these, there seems to be a merging of these experiences, such that the individual narrative cannot be separated from the family context. In Malene's case, she adopts her older brothers' weight management narratives, which structure her experience of the current intervention. Perhaps the most important finding of our study is that these shared understandings 
of weight management and the threat of overweight are a persistent part of the selfunderstandings in these families. This underlines Grøn's argument concerning how obesity runs in the family and is expected to run in the family (Grøn 2017, p. 185). Most of the families in our study see obesity as a perfectly normal thing that you are expected to accept or to deal with on a regular basis or throughout life and across generations.

This collective acceptance of continuous participation in interventions is related to discussions about adherence to implementation of lifestyle changes (Lee et al. 2008). It is well-known that poor adherence to long-term behavior change in lifestyle interventions is widespread. (Middleton et al. 2013). This is, however, not the case for the families in our study who have accepted the presence of constant attention to weight management issues. According to their own narratives, adherence to lifestyle interventions is relatively easy to relates to their everyday life. It is, however, also significant that the ensuing lack of long-term adherence is equally accepted. Leung et al. (2017) calls for more rigorous studies regarding factors related to adherence. Our study can be seen as a first step on the way to describing obesity narratives as a strong factor contributing to families' potential barriers and facilitators in relation to adherence to lifestyle interventions.

The question of how families are truly and mutually involved in any given intervention is of central importance here, and there is variation in the intensity of family focus and involvement across interventions (Lowry et al. 2007). It is, however, wellestablished that parent involvement is vital to both achieving and maintaining weight loss (Eg et al. 2017). The degree of actual and mutual familial involvement is difficult to pinpoint among the families in our study. While they all accept the presence of the threat of obesity as a persistent family problem, they also create individual narratives within the families. This discrepancy needs to be studied more closely in the future.

\section{Conclusions and Limitations}

We conclude that it is the families' own narratives and their collective perceptions of temporal meaning that structure their own implementation of the weight management intervention. Because of the familial narratives about overweight, the definition and aims of the intervention presented by the health professionals take a back seat.

As we have discussed, the families in our study have a great deal of knowledge about health and extensive experience with weight management. We pose the question whether such previous knowledge and experience within the families is used in a meaningful way in weight management interventions. Future weight management interventions should use the present findings to try to answer this question. In the paper, we have shown how familial narratives about overweight influence participation in a weight management intervention. Thus, it is useful to address these narratives when creating future weight management interventions that include families with life-long experiences with overweight. For instance, Christoffer's family did not adhere to the diet plan in the intervention but stuck with the rules from the weight-loss camp. By including narrative approaches in consultations concerning weight management interventions, health professionals would be more aware of the difficulties of incorporating diet plans in family life and of the fact that this is just another intervention in a long-lasting weight management process. By attending to the narratives of families with prior experiences with weight management, interventions could be designed to build on the families' experiences and proceed from the diet plan the families are already working with instead of offering just another set of rules. The narrative approach to weight management should take its point of departure in the life-world that each individual family creates through members' narratives about overweight. For example, the families in this study are all concerned about the threat of overweight, which is not related to being overweight.

Our findings about long-term effects of participating in obesity interventions need to be studied further across academic disciplines. In particular, sociological studies focusing on the broader relational implications are in need of more follow-up studies or studies that focus on the long-term effects of participating in overweight interventions. 
As we focused our research on joint narratives, it was important for us to interview the family members together. A potential disadvantage of interviewing family members together is that children may be influenced by their parents' or older siblings' opinions and refrain from stating their own. On the other hand, the emotional bonds between family members are stronger than they are in a normal group interview (Åstedt-Kurki et al. 2001), which is likely to inspire intimate narratives about their life together. In our case, the family interviews were especially valuable when examining how the narratives were constructed in real life through the interdependent relations within the family, as we actually gained access to this ongoing construction in real time. The interviewers actively encouraged all family members to be active throughout the interview, but some family members might not have expressed themselves fully in the family interviews due to the presence of other family members (Reczek 2014). This could also be the case with the not-so-active fathers in the interviews. Although nine fathers did participate in the interviews, they were rather quiet as the mothers and the children very much dominated the interviews. Another limitation is the potential risk of selection bias, in that healthcare professionals involved in the intervention helped in recruiting the families. This does not seem very likely, however, as the recruited families had both positive and negative things to say about the intervention.

In our view, a narrative approach offers a way of creating greater mutual understanding between health professionals and families enrolled in weight management interventions. Furthermore, it makes a differentiated approach to weight management possible and it functions as a way to identify individual families' needs. Therefore, we recommend that further research on weight management interventions that include families with life-long experiences with overweight focus on including narrative approaches in consultations.

In terms of how to apply our findings to the concrete development of weight management interventions, more research is definitely needed. We do, however, believe that an intervention that initially allows or even motivates the families to express their shared understanding of weight management could benefit in terms of being able tailor the intervention elements to the individual family.

Author Contributions: Conceptualization, A.M.A.M., G.K.T., B.H.R. and D.G.; methodology, A.M.A.M. and D.G.; formal analysis, A.M.A.M. and D.G.; investigation, A.M.A.M., D.H. and M.-B.L.H.; writingoriginal draft preparation, A.M.A.M. and D.G.; writing-review and editing, D.H., M.-B.L.H., G.K.T. and B.H.R.; project administration, D.G., G.K.T. and B.H.R. All authors have read and agreed to the published version of the manuscript.

Funding: This research received no external funding.

Institutional Review Board Statement: According to Danish legislation, interview studies require no approval from an ethics committee. The study followed the codes of ethics found in the Helsinki II Declaration. Moreover, the study was approved by the Danish Data Protection Agency (Rec. No.: NOH-2016-024).

Informed Consent Statement: Informed consent was obtained from all subjects involved in the study.

Data Availability Statement: Not applicably as the full dataset has not been translated.

Conflicts of Interest: The authors declare no conflict of interest.

\section{References}

Abbasi, Ali, Dorota Juszczyk, Cornelia H. M. van Jaarsveld, and Martin C. Gulliford. 2017. Body mass index and incident type 1 and type 2 diabetes in children and young adults: A retrospective cohort study. Journal of the Endocrine Society 1: 524-37. [CrossRef] [PubMed]

Al-Khudairy, Lena, Emma Loveman, Jill L. Colquitt, Emma Mead, Rebecca E. Johnson, Hannah Fraser, Joan Olajide, Marie Murphy, Rochelle Marian Velho, Claire O'Malley, and et al. 2017. Diet, physical activity and behavioural interventions for the treatment of overweight or obese adolescents aged 12 to 17 years. Cochrane Database of Systematic Reviews 6: CD012691. [CrossRef] [PubMed]

Andreassen, Pernille, Lone Grøn, and Kirsten K. Roessler. 2013. Hiding the Plot: Parents' Moral Dilemmas and Strategies When Helping Their Overweight Children Lose Weight. Qualitative Health Research 23: 1333-43. [CrossRef] [PubMed] 
Arai, Lisa, Monica Panca, Steve Morris, Katherine Curtis-Tyler, Patricia J. Lucas, and Helen M. Roberts. 2015. Time, monetary and other costs of participation in family-based child weight management interventions: Qualitative and systematic review evidence. PLOS ONE 10: e0123782. [CrossRef]

Boero, Nathalie. 2007. All the News that's Fat to Print: The American “Obesity Epidemic” and the Media. Qualitative Sociology 30: 41-60. [CrossRef]

Brownell, Kelly D., and Katherine Battle Horgen. 2004. Food Fight: The Inside Story of the Food Industry, America's Obesity Crisis, and What We Can Do about It. Chicago: Contemporary.

Conrad, Peter. 2007. Medicalization-Context, Characteristics, and Changes. In The Medicalization of Society: On the Transformation of Human Conditions into Treatable Disorders. Baltimore: Johns Hopkins University Press.

de Vries, Jantina. 2007. The Obesity Epidemic: Medical and Ethical Considerations. Science Engineering and Ethics 13: 55-67. [CrossRef]

Eg, Marianne, Kirsten Frederiksen, Marianne Vamosi, and Vibeke Lorentzen. 2017. How family interactions about lifestyle changes affect adolescents' possibilities for maintaining weight loss after a weight-loss intervention: A longitudinal qualitative interview study. Journal of Advanced Nursing 73: 1924-36. [CrossRef]

Golan, Moria. 2006. Parents as agents of change in childhood obesity-from research to practice. International Journal of Pediatric Obesity 1: 66-76. [CrossRef]

Good, Bryan. J., Michael M. J. Fisher, Sarah S. Willen, and Mary-Jo D. Good. 2010. Part II: Illness and Narrative, Body and Experience. Introduction. A Reader in Medical Anthropology. Oxford: Wiley-Blackwell Publishing.

Grøn, Lone. 2017. The Weight of the Family: Communicability as Alien Affection in Dansh Family Histories and Experiences of Obesity. ETHOS 45: 182-98. [CrossRef]

Hoeeg, Didde, Anne Martine Aaberg Mortil, Maj-Britt Lundsgaard Hansen, Grete Teilmann, and Dan Grabowski. 2020a. Families' adherence to a family-based childhood obesity intervention: A qualitative study on perceptions of authenticity. Health Communication 35: 110-18. [CrossRef]

Hoeeg, Didde, Dan Grabowski, and Ulla Christensen. 2018. Intra-familial stigmatization: An adverse outcome of a family-based health education intervention to reduce childhood obesity. Health Education 118: 227-38. [CrossRef]

Hoeeg, Didde, Ulla Christensen, Louise Lundby-Christensen, and Dan Grabowski. 2020b. Contextual Complexities in Implementing a Family-Based Childhood Obesity Intervention: The Perspectives of Enrolled Children and Their Parents. Children 7: 267. [CrossRef] [PubMed]

Lee, K., Y. Chin, Y. Loong, and A. Hejar. 2008. From compliance to adherence and concordance, what quantitative and qualitative studies have synthesized. Journal of Health Management 4: 36-61.

Leung, Alice W. Y., Ruth S. M. Chan, Mandy M. M. Sea, and Jean Woo. 2017. An overview of factors associated with adherence to lifestyle modification programs for weight management in adults. International Journal of Environmental Research and Public Health 14: 922. [CrossRef] [PubMed]

Lobstein, T., and R. Jackson-Leach. 2016. Planning for the worst: Estimates of obesity and comorbidities in school-age children in 2025. Pediatric Obesity 11: 321-25. [CrossRef]

Lowry, Kelly, Bethany J. Sallinen, and David M. Janicke. 2007. The Effects of Weight Management Programs on Self-Esteem in Pediatric Overweight Populations. Journal of Pediatric Psychology 32: 1179-95. [CrossRef]

Mead, Emma, Tamara Brown, Karen Rees, Liane B. Azevedo, Victoria Whittaker, Dan Jones, Joan Olajide, Giulia M. Mainardi, Eva Corpeleijn, Claire O'Malley, and et al. 2017. Diet, physical activity and behavioural interventions for the treatment of overweight or obese children from the age of 6 to 11 years. Cochrane Database Systematic Review 6: CD012651. [CrossRef]

Middleton, Kathryn R., Stephen D. Anton, and Michal G. Perri. 2013. Long-term adherence to health behavior change. American Journal of Lifestyle Medicine 7: 395-404. [CrossRef]

Most, Sebastian W., Birgitte Højgaard, Grete K. Teilmann, Jesper Andersen, Mette Valentiner, Michael O. Gamborg, and Jens-Christian Holm. 2015. Adoption of the children's obesity clinic's treatment (TCOCT) protocol into another Danish pediatric obesity treatment clinic. BMJ Pediatrics 15. [CrossRef]

Nestle, Marion, and Michael F. Jacobson. 2000. Halting the Obesity Epidemic: A Public Health Policy Approach. Public Health Reports 115: 12-24. [CrossRef]

Ochs, Elinor, and Lisa Capps. 1996. Narrating the Self. Annual Review of Anthropology 25: 19-43. [CrossRef]

Oude Luttikhuis, Hiltje, Louise Baur, Hanneke Jansen, Vanessa A. Shrewsbury, Claire O'Malley, Ronald P. Stolk, and Carolyn D. Summerbell. 2009. Interventions for treating obesity in children. Cochrane Database Systematic Review 1: CD001872. [CrossRef]

Rasmussen, Jens. 2004. Textual interpretation and complexity-Radical hermeneutics. Nordisk Pedagogik 24: 177-94.

Rasmussen, Mette, Trine P. Pedersen, and Pernille Due. 2015. Skolebørnsundersøgelse 2014 [Health Behaviour in School-aged Children 2014]. Copenhagen: National Institute of Public Health.

Reczek, Corinne. 2014. Conducting a Multi Family Member Interview Study. Family Process 53: 318-35. [CrossRef]

Ricoeur, Paul. 1980. Narrative Time. Critical Inquiry 7: 169-90. [CrossRef]

Skelton, J. A., C. Buehler, M. B. Irby, and J. G. Grzywacz. 2012. Where are family theories in family-based obesity treatment?: Conceptualizing the study of families in peadiatric weight management. International Journal of Obesity 36: 891-900. [CrossRef] [PubMed]

Steffen, Vibeke. 1997. Life stories and shared experience. Social Science and Medicine 45: 99-112. [CrossRef] 
WHO. 2018. Childhood Overweight and Obesity. World Health Organization. Available online: http://www.who.int/ dietphysicalactivity/childhood/en/ (accessed on 18 May 2018).

Åstedt-Kurki, Päivi, Eija Paavilainen, and Kristina Lehti. 2001. Methodological issues in interviewing families in family nursing research. Journal of Advanced Nursing 35: 288-93. [CrossRef] 